\title{
Factors affecting infant mortality in the general population: evidence from the 2016 Ethiopian demographic and health survey (EDHS); a multilevel analysis
}

Adhanom Gebreegziabher Baraki ${ }^{* *}$, Temesgen Yihunie Akalu ${ }^{1}$, Haileab Fekadu Wolde ${ }^{1}$, Ayenew Molla Lakew ${ }^{1}$ and Kedir Abdela Gonete ${ }^{2}$

\begin{abstract}
Background: Infant mortality is one of the leading public health problems globally; the problem is even more staggering in low-income countries. In Ethiopia seven in ten child deaths occurred during infancy in 2016. Even though the problem is devastating, updated information about the major determinants of infant mortality which is done on a countrywide representative sample is lacking. Therefore, this study was aimed to identify factors affecting infant mortality among the general population of Ethiopia, 2016.

Methods: A Community-based cross-sectional study was conducted in all regions of Ethiopia from January 18 to June 27, 2016. A total of 10,641 live births were included in the analysis. Data were analyzed and reported with both descriptive and analytic statistics. Bivariable and multivariable multilevel logistic regression models were fitted by accounting correlation of individuals within a cluster. Adjusted odds ratio (AOR) with $95 \%$ confidence interval was reported to show the strength of the association and its significance.

Results: A total of 10,641 live-births from the Ethiopian demographic and health survey (EDHS) data were included in the analysis. Being male infant ( $A O R=1.51 ; 1.25,1.82$ ), Multiple birth ( $A O R=5.49 ; 95 \% \mathrm{Cl}, 3.88-7.78)$, Preterm $(\mathrm{AOR}=8.47 ; 95 \% \mathrm{Cl} 5.71,12.57)$, rural residents $(\mathrm{AOR}=1.76 ; 95 \% \mathrm{Cl} ; 1.16,2.67)$, from Somali region $(\mathrm{AOR}=2.07 ; 1.29$, 3.33), Harari $(A O R=2.14 ; 1.22,3.75)$ and Diredawa $(A O R=1.91 ; 1.04,3.51)$ were found to be statistically significantly associated with infant mortality.

Conclusion: The study has assessed the determinants of infant mortality based on EDHS data. Sex of the child, multiple births, prematurity, and residence were notably associated with infant mortality. The risk of infant mortality has also shown differences across different regions. Since infant mortality is still major public health problem interventions shall be done giving more attention to infants who were delivered multiple and who are preterm.
\end{abstract}

Keywords: Infant mortality, Risk factors, Ethiopia

\footnotetext{
* Correspondence: adsh04@gmail.com

'Department of Epidemiology and Biostatistics, University of Gondar, College of Medicine and Health Sciences, Institute of Public Health, Gondar, Ethiopia Full list of author information is available at the end of the article
}

(c) The Author(s). 2020 Open Access This article is licensed under a Creative Commons Attribution 4.0 International License, which permits use, sharing, adaptation, distribution and reproduction in any medium or format, as long as you give appropriate credit to the original author(s) and the source, provide a link to the Creative Commons licence, and indicate if changes were made. The images or other third party material in this article are included in the article's Creative Commons licence, unless indicated otherwise in a credit line to the material. If material is not included in the article's Creative Commons licence and your intended use is not permitted by statutory regulation or exceeds the permitted use, you will need to obtain permission directly from the copyright holder. To view a copy of this licence, visit http://creativecommons.org/licenses/by/4.0/ The Creative Commons Public Domain Dedication waiver (http://creativecommons.org/publicdomain/zero/1.0/) applies to the data made available in this article, unless otherwise stated in a credit line to the data. 


\section{Background}

Over the past two decades, the world made substantial progress in reducing infant mortality. In 2017, an estimated 6.3 million children and young adolescents died due to mostly preventable causes. Children under the age of 5 years accounted for 5.4 million of these deaths, with 2.5 million deaths occurring in the first month of life, 1.6 million between age $1-11$ months, and 1.3 million between age 1-4 years [1]. According to studies done from 56 countries, infant mortality was one of the global public health concern and accounts for 144 deaths per 1000 live births [2].

In Sub-Saharan Africa, infant mortality has declined from 182 to 58 deaths per 1000 live births from 1990 to 2017. However, Globally, in 2017, half of all deaths under 5 years of age took place in sub-Saharan Africa, and another $30 \%$ in Southern Asia [1]. According to the 2016 Ethiopian Demographic and Health Survey (EDHS), the infant mortality rate was 48 deaths per 1000 live births, this constitutes seven in ten under-five deaths in the country [3]. Studying infant mortality is helpful to improve child health and maternal health as well [4].

Across the globe, different studies have been conducted to identify factors affecting infant mortality. Among these not attending antenatal care follow-up [5, 6], wealth index, birth interval [7], maternal age, maternal education $[8,9]$, domestic violence [10], healthrelated behavior like delaying in seeking health care [11], high poverty and living rural areas [12], and having metabolic disorders [13] were identified.

Even though the problem is high updated information about the major determinants of infant mortality which is done on a countrywide representative sample is lacking in Ethiopia. Therefore, this study was aimed to investigate determinants of infant mortality in Ethiopia, to identify problems to be focused on in order to sustain the reduction of infant mortality and improve survival.

\section{Methods}

\section{Study design and setting}

The data was obtained after permission is found from the Measure demographic and health survery (DHS) international program (https://dhsprogram.com/). EDHS 2016 is a community-based cross-sectional study that is conducted from January 18, 2016, to June 27, 2016. Ethiopia is situated in the Horn of Africa covering an area around 1.1 million square kilometers. Ethiopia is structured into nine regional states namely BenishangulGumuz, Tigray, Oromia, Afar, Amhara, Somali, Southern Nations Nationalities and Peoples (SNNP), Gambela, Harari and two city administrations, Addis Ababa and Dire Dawa. From the total population of the country, only $19 \%$ live in urban areas and more than $82 \%$ of the country's total population lives in the regional states of Amhara, SNNP, and Oromia.

\section{EDHS data and collection procedure}

The study used secondary data released by the central statistical agency (CSA). This is the fourth national representative survey done at the country level after the first three surveys conducted in 2000, 2005 and 2011. The primary aim of 2016 EDHS was to provide up-to-date information about the key demographic and health indicators. Both men and women aged 15-59 years were interviewed. Data was also collected from mothers or care-takers of live-born infants in the 5 years preceding the date of the interview. For this study, we have extracted data from the EDHS 2016 which was collected from eligible women 15-49 years of age and who were permanent residents of the selected households. The data was collected using a structured pretested questioner. Training was given for the data collectors before the start of the data collection.

\section{Sample size, and sampling technique}

The study included a total of 10,641 live births born from mothers who were interviewed about births in the preceding 5 years before the survey. We included only women in the reproductive age, from 15 to 49 years old.

The 2016 EDHS sample was stratified and selected in two stages. Each region was stratified into urban and rural areas, which yielded 21 sampling strata. Samples of enumeration areas (EAs) were selected independently in each stratum in two stages. Implicit stratification and proportional allocation were done at each of the lower administrative levels by sorting the sampling frame within each sampling stratum before sample selection. In the first stage, 645 EAs (202 from urban and 443 from rural) were selected with a proportional allocation of EA with an independent selection in each sampling stratum. A sampling frame was prepared for each selected EAs by listing households, this was used to select households in the second stage. In the second stage of selection, a fixed number of 28 households per cluster were selected with an equal probability systematic selection from the sampling frame. The survey interviewer interviewed only pre-selected households [3].

\section{Variables of the study}

The outcome variable for this study was infant mortality which was defined as the death of a live birth before the first birthday and it was estimated based on the information collected from the birth history section of the questioner which was administered to individual women.

The individual-level factors included in this study were; current age of the mother, age at first birth, sex of the household head, marital status, household wealth index, educational status both for the mother and the father, occupational status of the mother, size of the child at birth, number of living children in the household, child sex, birth order, duration of pregnancy, 
Table 1 Sociodemographic characteristics of study participants EDHS 2016

\begin{tabular}{|c|c|c|}
\hline Variable & Frequency & Percent \\
\hline \multicolumn{3}{|c|}{ Age (mean age:29.23 $\pm 6.5 \mathrm{SD}$ ) } \\
\hline $15-19$ & 404 & 3.8 \\
\hline $20-24$ & 2171 & 20.4 \\
\hline $25-29$ & 3161 & 29.71 \\
\hline $30-34$ & 2360 & 22.18 \\
\hline $35-39$ & 1697 & 15.95 \\
\hline $40-44$ & 647 & 6.08 \\
\hline $45-49$ & 201 & 1.89 \\
\hline \multicolumn{3}{|l|}{ Residence } \\
\hline Urban & 1974 & 18.55 \\
\hline Rural & 8667 & 81.45 \\
\hline \multicolumn{3}{|c|}{ Mothers educational status } \\
\hline No education & 6838 & 64.26 \\
\hline Primary & 2678 & 25.17 \\
\hline Secondary & 734 & 6.9 \\
\hline Higher & 391 & 3.67 \\
\hline \multicolumn{3}{|c|}{ Husbands educational status } \\
\hline No education & 5003 & 49.99 \\
\hline Primary & 3220 & 32.17 \\
\hline Secondary & 1015 & 10.14 \\
\hline Higher & 770 & 7.69 \\
\hline \multicolumn{3}{|l|}{ Mothers occupation } \\
\hline Housewife & 6307 & 59.27 \\
\hline Employed & 4334 & 40.73 \\
\hline \multicolumn{3}{|l|}{ Marital status } \\
\hline Never in union & 61 & 0.57 \\
\hline Married & 9903 & 93.06 \\
\hline Living with a partner & 105 & 0.99 \\
\hline Widowed & 135 & 1.27 \\
\hline Divorced & 328 & 3.08 \\
\hline Separated & 109 & 1.02 \\
\hline \multicolumn{3}{|l|}{ Wealth index } \\
\hline Poor & 5775 & 54.27 \\
\hline Medium & 1466 & 13.78 \\
\hline Rich & 3400 & 31.95 \\
\hline \multicolumn{3}{|l|}{ Religion } \\
\hline Orthodox & 3082 & 28.96 \\
\hline Catholic & 72 & 0.68 \\
\hline Protestant & 1862 & 17.50 \\
\hline Muslim & 5442 & 51.14 \\
\hline Traditional & 103 & 0.97 \\
\hline Other & 80 & 0.75 \\
\hline
\end{tabular}

Region
Table 1 Sociodemographic characteristics of study participants EDHS 2016 (Continued)

\begin{tabular}{lll}
\hline Variable & Frequency & Percent \\
\hline Tigray & 1033 & 9.71 \\
Afar & 1062 & 9.98 \\
Amhara & 977 & 9.18 \\
Oromia & 1581 & 14.86 \\
Somali & 1505 & 14.14 \\
Benshangul & 879 & 8.26 \\
SNNPR & 1277 & 12.0 \\
Gambela & 714 & 6.71 \\
Harari & 605 & 5.69 \\
Addis Ababa & 461 & 4.33 \\
Dire Dawa & 574 & 5.14 \\
Sex of Household head & & \\
Male & 8383 & 78.78 \\
Female & 2258 & 21.22 \\
\hline
\end{tabular}

preceding birth interval and whether the child is of multiple births or not, place of delivery, number of antenatal care (ANC) visits, number of tetanus toxoid (TT) injections during pregnancy and mode of delivery. Wealth index for the households was originally classified into five categories by DHS which was done using principal component analysis but for easy interpretation, we reclassified the wealth scores into three categories (poor, medium, rich). The community-level factors included in this study were residence and region.

\section{Data processing and analysis}

After data cleaning was done descriptive analysis was done using frequencies and percentages. A Chi-square test was done for all categorical independent variables to check the assumptions. Both bivariable and a multivariable multilevel logistic regression model was fitted by taking the clusters as a random effect. Variables having $p$-value $<0.2$ from the bivariable analysis were included in the final multivariable model. Variables having a p-value $<0.05$ from the multi-variable model were considered as having a significant association with infant mortality. Fixed effects were presented in terms of odds ratio with its $95 \%$ CI. The result of the random effect variation was checked using the intracluster correlation (ICC). The model goodness of fitness was checked using deviance information criteria (DIC). STATA version 14 was used for data analysis.

\section{Results}

Socio-demographic characteristics of study participants Of the total 10,641 live-births included in the analysis, $8667(81.5 \%)$ were the rural residents. The mean age of respondents was $29.23( \pm 6.5 \mathrm{SD})$. The majority, 
Table 2 Obstetric characteristics of participants EDHS 2016

\begin{tabular}{l} 
Variable \\
\hline Age of respondent at 1st bitt \\
$11-14$ \\
$15-19$ \\
$20-24$ \\
$25-29$ \\
$30-34$ \\
$35+$ \\
Size of the child at birth \\
Large \\
Average \\
Small \\
Don't know \\
Birth order \\
1 \\
$2-3$ \\
$4-6$ \\
$7+$
\end{tabular}

Number of living children

0
$1-2$
$3-4$
$5+$

Child sex

Male

5483

5158

Twins birth

Yes

No

278

10,363

Duration of pregnancy

Term
Preterm

10,455

186

Place of delivery

Home 7271

2832

Gov't hospital \& HC

Health post

191

Private hospital, clinic \&sector

263

NGO health facility

84

Number of TT injections during pregnancy (7193)

$\begin{array}{lll}0-1 & 4203 & 58.43 \\ \geq 2 & 2990 & 41.57\end{array}$

Delivery by CS

Yes

No

\subsection{5}

55.82

29.95

6.76.

1.42

0.21

30.20

41.53

27.16

1.11

20.36

31.37

31.81

16.46

0.71

34.32

30.35

34.61

51.53

48.47

2.61

97.39

98.26

1.74

68.33

26.61

1.79

2.47

0.79

58.43

4.57

2.87

97.13

Number of ANC visits during pregnancy $(n=7193)$

Table 2 Obstetric characteristics of participants EDHS 2016 (Continued)

\begin{tabular}{lll}
\hline Variable & Frequency & Percent \\
\hline No visit & 2481 & 34.49 \\
$1-3$ visit & 2092 & 29.08 \\
$\geq 4$ visit & 2601 & 36.16 \\
Don't know & 19 & 0.26 \\
\hline
\end{tabular}

$3161(29.7 \%)$, of the mothers were in the age group of 25-29 years. About two-thirds (6838) and half (5003) mothers and their partners did not have any formal education respectively. The larger proportion, 6307(59.3\%), of the mothers were housewives and a large number, 9903 (93.06\%), of the participants were married. More than half, 5775(54.3\%), of the infants were from households categorized in poor income (Table 1).

\section{Obstetric related characteristics}

More than half, 5940(55.8\%) of mothers give their first birth when their age was between 15 and 19. Almost two-thirds (63\%) of mothers give their second to sixth births and about 3230 mothers have $3-4$ live births. The average number of live births was 3 (IQR: 2, 5). The majority of live-births had an average size when they were born. More than half, 7271(68.33\%) of the mothers delivered at home, and most, 10,391(97.65\%), of them gave birth at term (Table 2).

\section{Determinants of infant mortality}

Based on the multivariable multilevel logistic regression output residence, region, child sex, multiple births, and duration of pregnancy were found to be significantly associated with infant death.

The odds of infant death among male children was 1.51 times higher as compared to females $(\mathrm{AOR}=1.51 ; 1.25$, 1.82 ). The odds of death was 5.49 ( $\mathrm{AOR}=5.49 ; 95 \% \mathrm{CI}$, 3.88-7.78) times higher among multiple births as compared to singletons. Preterm infants were $8.47(\mathrm{AOR}=$ 8.47; 95\% CI 5.71, 12.57) times more likely to die as compared to infants born at term. The risk of infant mortality among rural residents was $1.76(\mathrm{AOR}=1.76 ; 95 \% \mathrm{CI} ; 1.16$, 2.67) times higher when compared to urban residents. Mortality risk was higher among children born in the east of Ethiopia; the risk of infant death among infants born in Somali $(\mathrm{AOR}=2.07 ; 1.29,3.33)$, Harari $(\mathrm{AOR}=2.14 ; 1.22$, 3.75 ) and Diredawa (AOR $=1.91 ; 1.04,3.51$ ) was higher as compared to Tigray region (Table 3 ).

\section{Discussions}

The infant mortality rate in Ethiopia was 48 per 1000 live births in 2016. In this study, we have found sex of the child, multiple birth, duration of pregnancy, 
Table 3 Multilevel multivariable logistic regression output for determinants of infant mortality among infants in Ethiopia, 2016

\begin{tabular}{ll}
\hline Variable & Crude OR $(95 \%$ \\
\hline Age & \\
$15-19$ & 1.00 \\
$20-24$ & $0.94(0.59,1.49)$ \\
$25-29$ & $0.74(0.47,1.16)$ \\
$30-34$ & $0.64(0.40,1.02)$ \\
$35-39$ & $0.81(0.50,1.31)$ \\
$40-44$ & $0.74(0.42,1.30)$ \\
$45-49$ & $1.28(0.65,2.54)$
\end{tabular}

\section{Model I}

AOR $(95 \% \mathrm{Cl})$

\section{Mothers' educational Status}

No education

Secondary and above

Wealth Index

\section{Poor \\ Medium}

Rich

\section{Sex of Household head}

Male

Female

\section{Birth order}

1

$2-3$

4-6

$7+$

\section{Child sex}

Male

Female

\section{Twin birth}

No

Yes

\section{Duration of pregnancy}

Pre-term
Term

Place of delivery

Home

1.00

Government hospital/health center

Health post

$0.77(0.62,0.97)$

$0.74(0.34,1.60)$

Private and NGO HF

$1.44(1.15,1.79)$

$1.11(0.81,1.53)$

1.00

$1.26(0.99,1.60)$

1.00

$0.94(0.70,1.25)$

$0.77(0.59,1.01)$

$0.79(0.60,1.02)$

1.00

$1.52(1.27,1.83)$

1.00

1.00

$5.44(3.91,7.58)$

$8.16(5.61,11.87)$

1.00

$0.67(0.37,1.23)$
1.00

$0.89(0.55,1.44)$

$0.71(0.43,1.18)$

$0.57(0.33,1.00)$

$0.64(0.35,1.14)$

$0.56(0.28,1.10)$

$1.02(0.46,2.27)$

$1.49(1.05,2.11)$

$1.29(0.88,1.89)$

1.00

1.00

$1.74(1.29,2.33)$

1.00
$1.51(0.98,2.30)$

$1.26(0.83,1.90)$

1.00

$1.20(0.93,1.55)$

$0.93(0.67,1.31)$

1.00

$1.27(0.99,1.62)$

1.00

$1.00(0.64,1.56)$

$0.80(0.55,1.17)$

$0.84(0.62,1.15)$

1.00

$1.50(1.24,1.82)$

1.00

1.00

$5.53(3.90,7.83)$

$7.80(5.29,11.50)$

1.00

1.00

$0.80(0.62,1.03)$

$0.77(0.35,1.70)$

$0.68(0.35,1.33)$
1.00

$1.83(1.30,2.57)$

1.00
Model III

AOR (95\% Cl)

1.00

$0.92(0.57,1.48)$

$0.77(0.46,1.29)$

$0.66(0.37,1.16)$

$0.75(0.42,1.36)$

$0.66(0.33,1.32)$

$1.22(0.55,2.72)$

$1.25(0.80,1.93)$

$1.12(0.73,1.71)$

1.00

$1.01(0.76,1.35)$

$0.83(0.58,1.18)$

1.00

$1.28(0.99,1.65)$

1.00

$1.13(0.73,1.77)$

$0.89(0.61,1.30)$

$0.89(0.65,1.22)$

1.00

$1.51(1.25,1.82)^{*}$

1.00

1.00

$5.49(3.88,7.78)^{*}$

$8.47(5.71,12.57)^{*}$

1.00

1.00

$0.89(0.68,1.17)$

$0.78(0.36,1.72)$

$0.76(0.38,1.52)$

1.00

$1.76(1.16,2.67)^{*}$

Region

Tigray

sidence

Urban

1.00 
Table 3 Multilevel multivariable logistic regression output for determinants of infant mortality among infants in Ethiopia, 2016 (Continued)

\begin{tabular}{|c|c|c|c|c|}
\hline Variable & Crude OR (95\% Cl) & $\begin{array}{l}\text { Model I } \\
\text { AOR (95\% Cl) }\end{array}$ & $\begin{array}{l}\text { Model II } \\
\text { AOR (95\% Cl) }\end{array}$ & $\begin{array}{l}\text { Model III } \\
\text { AOR (95\% Cl) }\end{array}$ \\
\hline Afar & $2.02(1.24,3.28)$ & $1.96(1.21,3.18)$ & & $1.66(0.99,2.76)$ \\
\hline Amhara & $1.53(0.92,2.54)$ & $1.48(0.89,2.45)$ & & $1.34(0.79,2.25)$ \\
\hline Oromia & $1.51(0.95,2.42)$ & $1.44(0.90,2.29)$ & & $1.26(0.78,2.05)$ \\
\hline Somali & $2.14(1.35,3.37)$ & $2.18(1.38,3.43)$ & & $2.07(1.29,3.33)^{*}$ \\
\hline Benshangul & $1.84(1.11,3.06)$ & $1.75(1.06,2.91)$ & & $1.59(0.94,2.67)$ \\
\hline SNNPR & $1.47(0.90,2.38)$ & $1.41(0.87,2.29)$ & & $1.42(0.87,2.33)$ \\
\hline Gambela & $1.53(0.88,2.64)$ & $1.60(0.93,2.76)$ & & $1.28(0.73,2.27)$ \\
\hline Harari & $1.93(1.12,3.33)$ & $2.15(1.25,3.72)$ & & $2.14(1.22,3.75)^{*}$ \\
\hline Addis Ababa & $0.94(0.47,1.88)$ & $1.60(0.75,3.39)$ & & $1.3(0.58,2.89)$ \\
\hline Dire Dawa & $1.54(0.86,2.77)$ & $1.88(1.03,3.40)$ & & $1.91(1.04,3.51)^{*}$ \\
\hline \multicolumn{5}{|l|}{ Null Model } \\
\hline Intercept & $0.52(0.39,0.71)$ & $0.46(0.31,0.66)$ & $0.49(0.36,0.69)$ & $0.45(0.30,0.67)$ \\
\hline Log-Likelihood & -2021.15 & -2004.79 & -1909.66 & -1898.87 \\
\hline Deviance & 4042.3 & 4009.58 & 3819.32 & 3797.74 \\
\hline
\end{tabular}

*P-value $<0.05$

Model I: community-level factor Model II: individual-level factor Model III: Both community and individual-level factors

residence, and region to be significantly associated with infant mortality.

The infant mortality rate (48 per 1000 live birth) in Ethiopia was consistent with the infant mortality rate of World Health Organization (WHO) African regions (51 per 1000 live births), but it was higher than most of the developed countries like United States (5.96 per 1000 live births) [14], Canada (5.2 per 1000 live births) [15] and WHO European region (8 per 1000 live births). However, the infant mortality in Ethiopia was significantly lower than several other countries like Afganistan (110.6 per 1000 live births), Somalia (94.8 per 1000 live births), and Nigeria (69.8 per 1000 live births) [16]. The main reason for this discrepancy could be the difference in socio-economic status, health facility coverage, and other infrastructures.

The odds of infant death were higher among male infants as compared to females. This finding is in line with studies conducted in Kenya [17] and a multicenter study [18] but another study conducted in Brazil found no association between infant death and sex of the baby [8]. The higher risk of death among male infants could be explained by sex differences in genetic and biological makeup, with boys being biologically weaker and more susceptible to diseases and premature death [19].

The risk of death among infants born two or more was higher than singletons, which is supported by other studies conducted in Brazil $[8,20]$ Kenya [17] and Greece [21, 22]. Having multiple births can be a challenge for the mother to give care which makes the infants at risk of malnutrition and infections. The risk of being low birth weight also increases when there is multiple pregnancy and this affects the children survival [23].

Infants born preterm were more likely to die as compared to the term infants. This result is consistent with other studies $[8,24]$. The reason could be respiratory morbidity, feeding difficulties, hyperbilirubinemia, temperature instability, infection, and hypoglycemia which is more common among preterm infants than infants born at term [25-29].

The odds of infant death among rural residents was higher than that of the urban. This finding is consistent with other studies $[12,30]$. The reason behind could be the lack of access to health institutions to have ANC followups or lack of media exposure which in turn affects their knowledge and practice of care for the infant [31,32].

The odds of death among infants living in the eastern part of Ethiopia (Harari, Dire Dawa, and Somali) was higher than infants in Tigray, the northern part of the country. The possible reason could be drug abuse especially chat chewing which is more common in these areas which results in child neglect and poor healthcareseeking behavior [3]. Mothers who use chat/ abuse drugs are also more likely to deliver a baby with low birth weight due to the effect of chat on the growth of fetus by inhibiting uteroplacental blood flow this, in turn, affects the survival of the baby [33, 34]. These regions are also known for socio-economic vulnerability and food insecurity leading to malnutrition and infant death [35].

The significant determinant of infant mortality in several studies, maternal education $[8,9]$, was not significantly associated with infant death in this study. The possible reason could be the difference in the content 
and quality of the education provided across different countries. Besides, the sample size difference could also be another contributor to this discrepancy.

\section{Conclusions}

The study has assessed the determinants of infant mortality based on EDHS data. Sex of the child, multiple births, duration of pregnancy, and residence were significantly associated with infant mortality. The risk of infant mortality has also shown differences across different regions. Since infant mortality is still major public health problem interventions shall be done giving more attention to women with multiple births and infants delivered before term. Expanding the primary health care network in more susceptible regions would also limit infant death.

\section{Limitations}

These study shares limitations of cross-sectional studies, therefore, may not be strong in establishing a causeeffect relationship. We were not directly involved in the data collection which makes us uncertain about the data quality.

\section{Abbreviations \\ ANC: Antenatal Care; AOR: Adjusted Odds Ratio; Cl: Confidence Interval; CSA: Central Statistical Agency; DHS: Demographic and Health Survey; DIS: deviance information criteria; EA: Enumeration Area; EDHS: Ethiopian Demographic and Health Survey; ICC: Intracluster correlation; SD: Standard Deviation; SNNP: Southern Nations Nationalities and Peoples; TT: Tetanus Toxoid}

\section{Acknowledgments}

We would like to thank the Measure DHS international program for providing the data set.

\section{Authors' contributions}

AGB, TYA, HFW, KAG, and AML have actively participated during conception, data extraction, analysis and interpretation of data. All authors have read and approved the final version of the manuscript.

\section{Funding}

None.

\section{Availability of data and materials}

Data is available on https://dhsprogram.com/data/available-datasets.cfm

\section{Ethics approval and consent to participate}

Permission was obtained to use the EDHS data from the Measure DHS international program. The data is publicly available and has no personal identifiers.

\section{Consent for publication}

Not applicable.

\section{Competing interests}

The authors declare that there is no competing interest.

\section{Author details}

${ }^{1}$ Department of Epidemiology and Biostatistics, University of Gondar, College of Medicine and Health Sciences, Institute of Public Health, Gondar, Ethiopia. ${ }^{2}$ Department of Human Nutrition, University of Gondar, College of Medicine and Health Sciences, Institute of Public Health, Gondar, Ethiopia.
Received: 13 May 2019 Accepted: 8 May 2020

Published online: 15 May 2020

\section{References}

1. UNICEF. Levels \& Trends in child mortality; 2018.

2. Rutstein SO. Factors associated with trends in infant and child mortality in developing countries during the 1990s. Lancet Glob Health. 2000;78:10.

3. Ethiopia. Ethiopia Demographic and Health Survey, 2016. ICF International, central Statistical Agency; 2017.

4. Finnerty P, Provost L, O'Donnell E, Selk S, Stephens K, Kim J, et al. Using infant mortality data to improve maternal and child health programs: an application of statistical process control techniques for rare events. Matern Child Health J. 2019:23(6):739.

5. Dube L, Taha M, Asefa H. Determinants of infant mortality in community of Gilgel gibe field research center, Southwest Ethiopia: a matched case control study. BMC Public Health. 2013;13:401.

6. Leal MD, Bittencourt SD, Torres RM, Niquini RP, Souza PR Jr. Determinants of infant mortality in the Jequitinhonha Valley and in the north and northeast regions of Brazil. Rev Saude Publica. 2017:51(0):12.

7. Khadka KB, Lieberman LS, Giedraitis V, Bhatta L, Pandey G. The socioeconomic determinants of infant mortality in Nepal: analysis of Nepal demographic health survey, 2011. BMC Pediatr. 2015:15:152.

8. Santos SL, Santos LB, Campelo V, Silva AR. Factors associated with infant mortality in a northeastern Brazilian capital. Rev Bras Ginecol Obstet. 2016; 38(10):482-91

9. Kiross GT, Chojenta C, Barker D, Tiruye TY, Loxton D. The effect of maternal education on infant mortality in Ethiopia: a systematic review and metaanalysis. PLoS One. 2019;14:7.

10. Varghese $\mathrm{S}$, Prasad $\mathrm{JH}$, Jacob KS. Domestic violence as a risk factor for infant and child mortality: a community-based case-control study from southern India. Natl Med J India. 2013;26(3):142-6.

11. Koffi AK, Wounang RS, Nguefack F, Moluh S, Libite PR, Kalter HD. Sociodemographic, behavioral, and environmental factors of child mortality in eastern region of Cameroon: results from a social autopsy study. J Glob Health. 2017;7(1):010601.

12. Mohamoud YA, Kirby RS, Ehrenthal DB. Poverty, urban-rural classification and term infant mortality: a population-based multilevel analysis. BMC Pregnancy Childbirth. 2019;19(1):40

13. de Bitencourt FH, Schwartz IVD, Vianna FSL. Infant mortality in Brazil attributable to inborn errors of metabolism associated with sudden death: a time-series study (2002-2014). BMC Pediatr. 2019;19(1):52.

14. Mathews T, MacDorman MF, Thoma ME. Infant mortality statistics from the 2013 period linked birth/infant death data set; 2015.

15. Collins SA, Surmala P, Osborne G, Greenberg C, Bathory LW, EdmundsPotvin S, et al. Causes and risk factors for infant mortality in Nunavut, Canada 1999-2011. BMC Pediatr. 2012;12(1):190.

16. World Population Review: Infant mortality rate by country. https:// worldpopulationreview.com/countries/infant-mortality-rate-by-country/. Accessed 14 Apr 2020

17. Mutunga CJ. Environmental determinants of child mortality in Kenya. InHealth inequality and development. London: Palgrave Macmillan. 2011; 89-110.

18. Hobcraft JN, McDonald JW, Rutstein SO. Demographic determinants of infant and early child mortality: a comparative analysis. Popul Stud. 1985; 39(3):363-85.

19. Pongou R. Why is infant mortality higher in boys than in girls? A new hypothesis based on preconception environment and evidence from a large sample of twins. Demography. 2013;50(2):421-44.

20. HGD S, SMD A, AMR S, WOD C, Mesas AE. Risk factors for infant mortality in a municipality in southern Brazil: a comparison of two cohorts using hierarchical analysis. Cadernos de Saúde Pública. 2012; 28(10):1915-26

21. Dimitriou G, Fouzas S, Georgakis V, Vervenioti A, Papadopoulos VG, Decavalas $\mathrm{G}$, et al. Determinants of morbidity in late preterm infants. Early Hum Dev. 2010:86(9):587-91.

22. Mathews T, MacDorman MF. Infant mortality statistics from the 2010 period linked birth/infant death data set. Natl Vital Stat Rep. 2013:62(8):1-26.

23. Luke $B$, Keith LG. The contribution of singletons, twins and triplets to low birth weight, infant mortality and handicap in the United States. J Reprod Med. 1992:37(8):661-6. 
24. Kramer MS, Demissie K, Yang H, Platt RW, Sauvé R, Liston R. Fetal, system IHSGotCPS: the contribution of mild and moderate preterm birth to infant mortality. Jama. 2000;284(7):843-9.

25. Wang ML, Dorer DJ, Fleming MP, Catlin EA. Clinical outcomes of near-term infants. Pediatrics. 2004;114(2):372-6.

26. Dudell GG, Jain L. Hypoxic respiratory failure in the late preterm infant. Clin Perinatol. 2006;33(4):803-30.

27. Jain L. Respiratory morbidity in late-preterm infants: prevention is better than cure! Am J Perinatol. 2008;25(02):075-8.

28. Bhutani VK, Johnson L. Kernicterus in late preterm infants cared for as term healthy infants. Semin Perinatol. 2006;30(2):89-97.

29. Garg M, Devaskar SU. Glucose metabolism in the late preterm infant. Clin Perinatol. 2006;33(4):853-70.

30. Agha S. The determinants of infant mortality in Pakistan. Soc Sci Med. 2000; 51(2):199-208.

31. Dairo M, Owoyokun K. Factors affecting the utilization of antenatal care services in Ibadan, Nigeria. Benin J Postgrad Med. 2010;12:1.

32. Zelalem Ayele D, Belayihun B, Teji K, Admassu Ayana D. Factors affecting utilization of maternal health Care Services in Kombolcha District, eastern Hararghe zone, Oromia regional state, eastern Ethiopia. Int Sch Res Notices. 2014;2014:1.

33. Habel L, Kaye K, Lee J. Trends in reporting of maternal drug abuse and infant mortality among drug-exposed infants in new York City. Women Health. 1990;16(2):41-58.

34. Mwenda J, Arimi M, Kyama M, Langat D. Effects of khat (Catha edulis) consumption on reproductive functions: a review. East Afr Med J. 2003: 80(6):318-23.

35. Sileshi M, Kadigi R, Mutabazi K, Sieber S. Analysis of households' vulnerability to food insecurity and its influencing factors in east Hararghe, Ethiopia. J Econ Struct. 2019;8(1):41.

\section{Publisher's Note}

Springer Nature remains neutral with regard to jurisdictional claims in published maps and institutional affiliations.

Ready to submit your research? Choose BMC and benefit from:

- fast, convenient online submission

- thorough peer review by experienced researchers in your field

- rapid publication on acceptance

- support for research data, including large and complex data types

- gold Open Access which fosters wider collaboration and increased citations

- maximum visibility for your research: over $100 \mathrm{M}$ website views per year

At $\mathrm{BMC}$, research is always in progress.

Learn more biomedcentral.com/submissions 